УДК

\title{
ОСНОВНЫЕ ПРИЧИНЫ КРИЗИСНЫХ СИТУАЦИЙ В СОЦИАЛЬНО-ЭКОНОМИЧЕСКОМ РАЗВИТИИ ПРОБЛЕМНЫХ РЕГИОНОВ
}

\author{
Кавтарова Хава Хизировна \\ Абубакарова Тамила Исламовна \\ Куразова Диана Алдамовна \\ старший преподаватель кафедры \\ «Учет, анализ и аудит в цифровой экономике» \\ Институт экономики и финансов \\ ФГБОУ ВО «Чеченский государственный университет»
}

Аннотация. Предмет. Проблемы социально-экономического развития регионов в современных условиях. Тема. Основные причины кризисных ситуаций в социально-экономическом развитии проблемных регионов. Цель работы. Выявление и исследование основных причин кризисных ситуаций проблемных регионов. Методология проведения работы. Методологическую основу проведенного исследования составили научные работы российских ученых. Исследование проводилось с учетом системного подхода. Результаты работы. Результаты работы показывают, что построение эффективной системы институтов социально-экономического развития должны вестись на основе системного подхода и учета внутренних аспектов развития регионов: деградации природной среды, снижения человеческого потенциала, морального и физического износа основных фондов, ошибок в управлении регионом в целом и его частями. Область применения результатов. Представленные результаты могут быть использованы пи разработке программ регионального развития. Выводы. Низкая эффективность и отдача институтов регионального развития напрямую связана с нерешенностью внутренних проблем, среди которых особое место занимает коррумпированность, теневая экономика, экономическая преступность и политическая нестабильность. В итоге, институты регионального развития в проблемных регионах должны выстраиваться с учетом существующих барьеров и нацелены на решения внутренних проблем.

Ключевые слова: регион, проблемные регионы, кризисные ситуации, экономическое отставание, отсталые регионы, депрессивные регионы. 


\title{
THE MAIN CAUSES OF CRISIS SITUATIONS IN THE SOCIO- ECONOMIC DEVELOPMENT OF PROBLEM REGIONS
}

\section{Kavtarova Khava Khizirovna}

Student

Abubakarova Tamila Islamovna

Student

Kurazova Diana Aldamovna

Senior lecturer of the department «Accounting, analysis and audit in the digital economy»

Institute of Economics and Finance FGBOU VO « Chechen state University»

\begin{abstract}
Subject. Problems of socio-economic development of regions in modern conditions. Topic. Themaincausesofcrisissituationsinthesocioeconomicdevelopmentofproblemregions. Purpose of work. Identification and research of the main causes of crisis situations in problem regions. Methodology of the work. The methodology basis of the research was made up of scientific works of Russian scientists. The study was conducted using a systematic approach. Result of work. The results of the works how that the construction of an effective system of institutions for socio-economic development should be based on a systematic approach and take into account internal aspects of regional development: degradation of the natural environment, reduction of human potential, moral and physical deterioration of fixed assets, mistakes in the management of the regionals a whole and it spurts. The scope of the results. There salts presented can be use din the development of regional development programs. Conclusions. The low efficiency and impact of regional development institutions is directly related to the unre solved internal problems, among which corruption, the shadow economy, economic crime and political instability occupy a special place. As a result, regional development institutions in problem regions should be built taking intact count existing barrier sand aimed at solving internal problems.
\end{abstract}

Keywords: region, problem regions, crisis situations, economic backwardness, backward regions, depressed regions.

Финансовое место нынешней Российской Федерации содержит разную структуру согласно уровню финансового, также общественного формирования собственных ареалов. Отличия ареалов обуславливаются, как 
беспристрастными, также индивидуальными условиями. Конкретные условия обладают связью с естественно-климатическими критериями, географическим расположением, многознаменательными, также социо-культурными отличительными чертами, индивидуальные условия выявляются в ходе их осуществления в абсолютно всех степенях управления областной политикой. Это приводит к тому, что определенные ареалы имеют устойчивое формирование, также имеют все шансы самостоятельно улаживать образующиеся трудности, прочие, в силу вышеперечисленных факторов никак не имеют все шансы найти решения трудностей на пути собственного становления, также имеют необходимость в помощи снаружи, более того подобные ареалы установлено именовать проблематичными.

Основанием для стабильного формирования Российской Федерации считается равновесие в формировании абсолютно всех субъектов государства, также своего рода «препятствием» считается присутствие проблематичных ареалов, какими считаются территориальные образования, экономически, политически, социально, экологически неудовлетворяющими потенциалу, также стимулам формирования государства [1.С.30].

Главными высококачественными свойствами проблематичных ареалов считаются соответствующее нюансы, продемонстрированные в рисунке 1.

Особая кризисность проявления той или иной крупной проблемы, создающей угрозу социально-экономическому положению в стране, политической стабильности, экологическому равновесию

Наличие ресурсного потенциала (производственного, научнотехнического, трудового, природного), использование которого особенно важно для национальной экономики

Особое значение геополитического и

геоэкономического положения региона для стратегических интересов страны

Недостаток у региона собственных финансовых ресурсов для решения проблем общенационального и мирового значения

\section{Рис. 1. Основные качественные признаки проблемных регионов}

Источник: [4.C.38] 
По территории проблемное районирование не носит сплошного характера, в качестве таких регионов могут рассматриваться следующие типы территорий, представленные на рисунке 2.

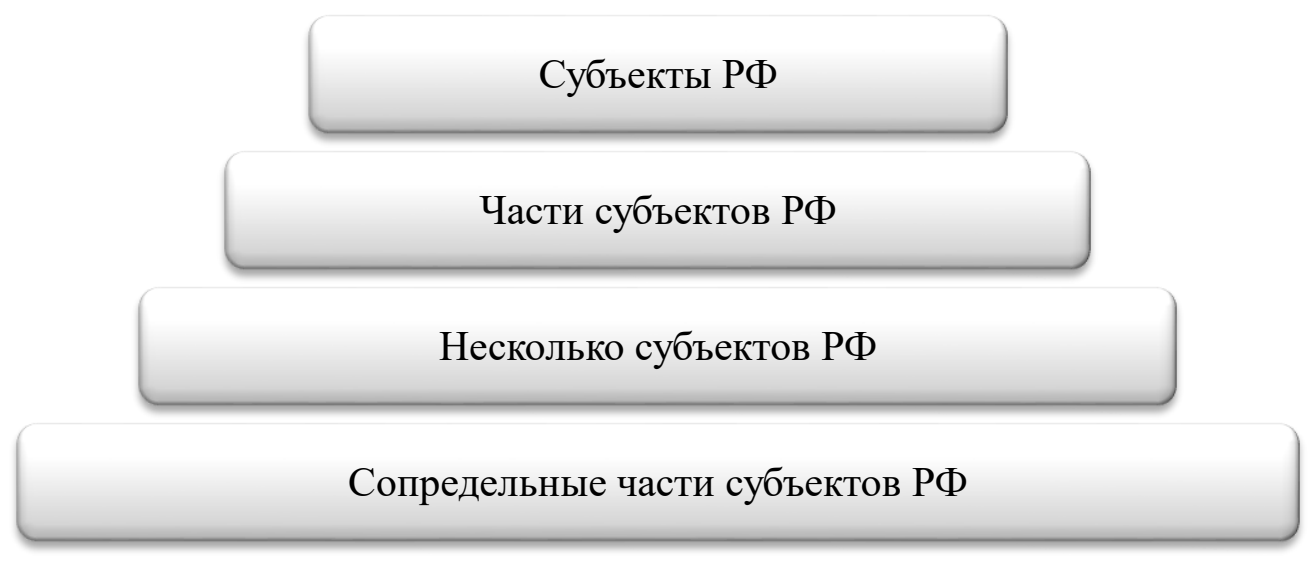

Рис. 2. Типы проблемных территорий

Проблемные регионы целесообразно рассматривать по двум аспектам, представленным на рисунке 3 .

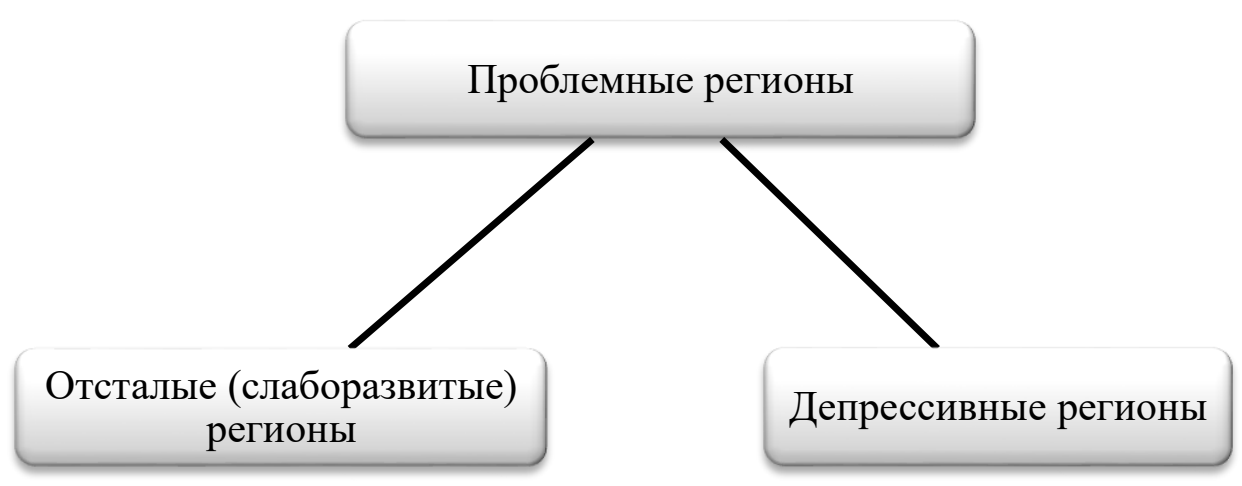

Рис. 3. Типологизация проблемных регионов

Источник: [3.С. 5]

К неразвитым проблемным ареалам принадлежат местности, которые обладают обычно невысокой степенью жизни местных жителей, в сопоставлении с ведущей массой ареалов государства. Общественнофинансовая стратегия подобных ареалов располагается в пребывании продолжительного застоя, со свойственно невысокой насыщенностью производственно-хозяйственной работы, не достаточно диверсифицированной общеотраслевой текстурой индустрии, невысоким научно-техническим потенциалом, малоразвитой общественной областью. В Некоторых Случаях 
общественно-финансовое состояние подобных ареалов, обременено трудностями общественно-политического, народного, преступного также природоохранного нрава.

Подавленные ареалы обладают базисным различием с неразвитыми землями, раскрывающимися в наиболее невысоких, нежели в обычном согласно государству, нынешних общественно-финансовых признаках. В прошлом подавленные ареалы были общественно также экономически сформированы, также принадлежали к местностям с довольно значительной степенью собранного производственно-технического потенциала, существенной части индустриального изготовления в структуре хозяйства, высочайшей степени квалификации сотрудников. В силу разных факторов, раскрывающихся в падении спроса на главную продукцию района, либо уменьшения ее конкурентоспособности, истощение естественных ресурсов, либо смещении в худшую сторону геологических обстоятельств и т.д. Данные ареалы утратили собственную финансовую значимость также областные достоинства [3.Со. 6].

Главные нюансы факторов переломных обстановок во проблематичных ареалах презентованы в рисунке 4 .

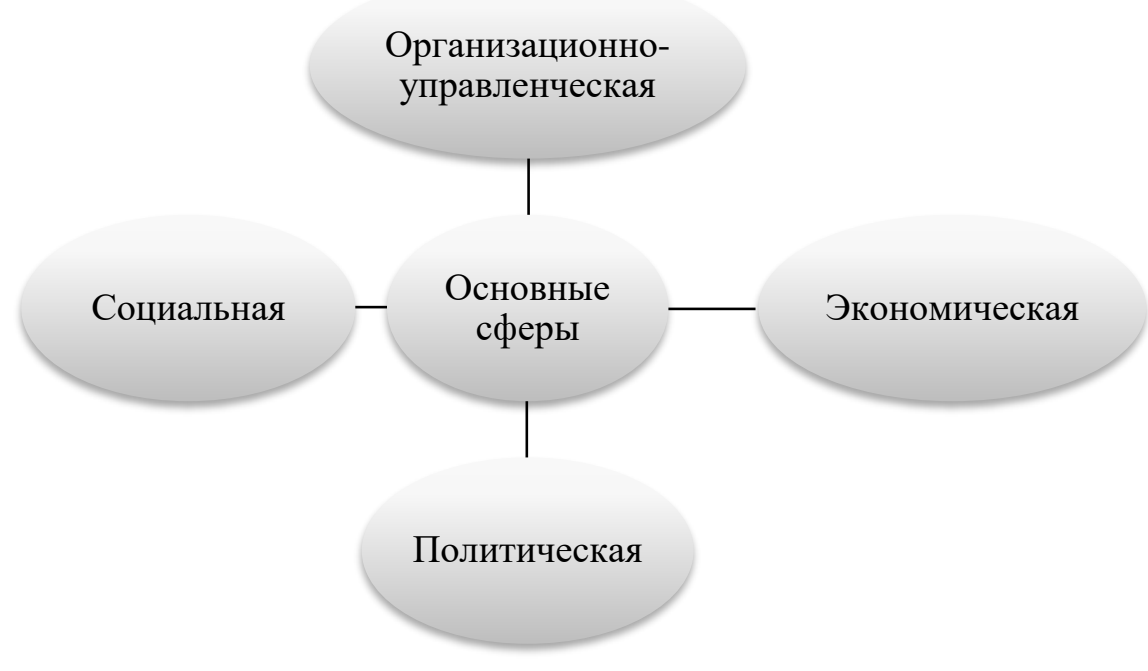

\section{Рис. 4. Основные сферы причин проблемных регионов}

Источник: [3.С. 10]

Во всем обилии ареалов единого финансового пространства РФ есть коекакие экономически проблемные ареалы с беспристрастно объективно неразрешимыми в направлении нескольких 10-ов лет задачами, которые выливаются из индивидуальностей их природного и исторического 
становления и территориального местопребывания, которые не предусматриваются единообразной, центростремительной политикой территориального управления [5. С. 10]. К этим ареалам относятся все республики Северного Кавказа, с их неразрешимыми хозяйственными задачами: замедляющимися темпами реальной экономики, экономной несостоятельностью, глобальной безработицей, общественным и финансовым неравенством, этно-конфессиональными инцидентами, которые в совокупности понижают эффективность мер социально-экономического становления. В ряде ведущих оснований неразрешимости задач становления этих ареалов возможно обозначить ряд качеств, которые представлены на рисунке 5.

\title{
Политическая нестабильность
}

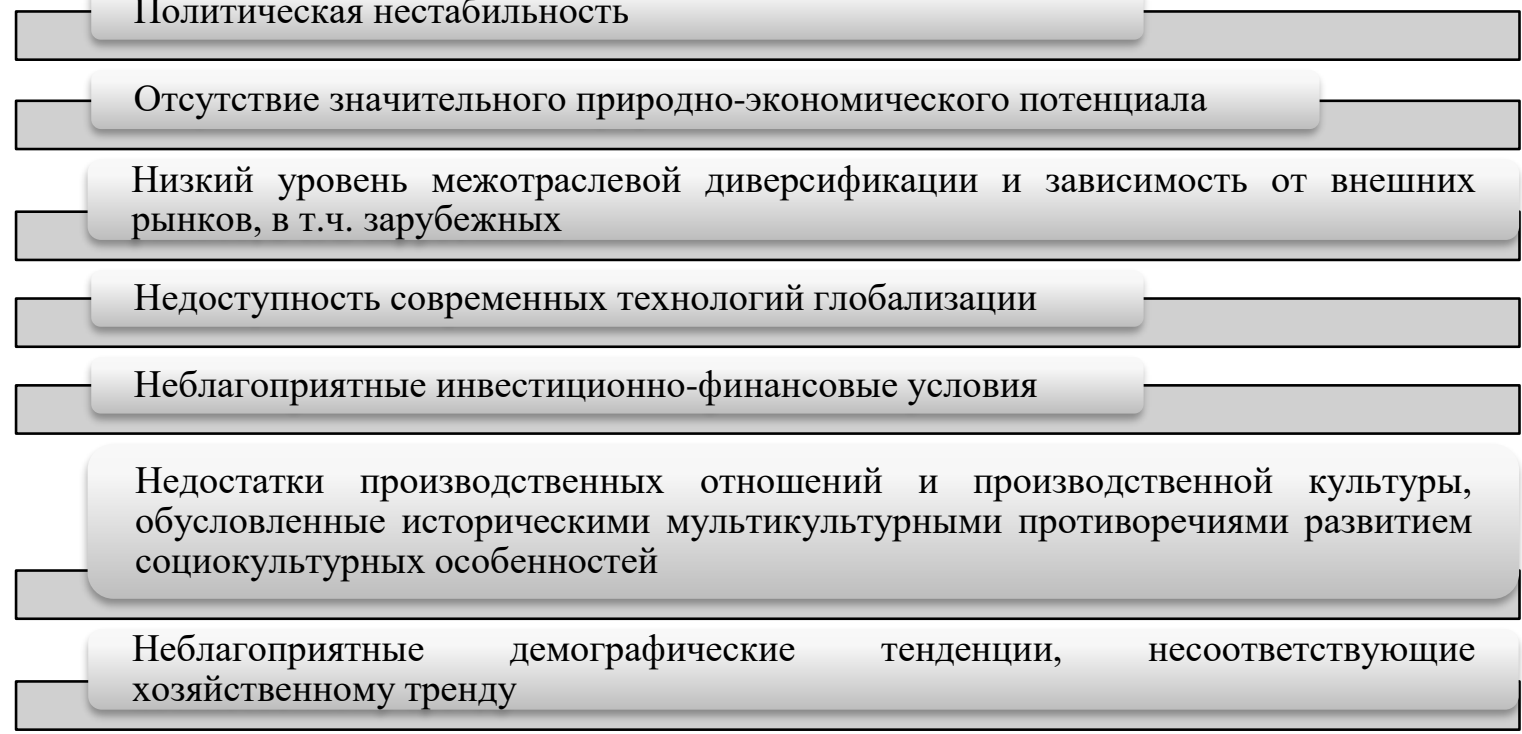

\section{Рис. 5. Основные причины неразрешимости проблем экономического отставания проблемных регионов}

\author{
Источник: [7.С. 39]
}

Переход РФ к рыночным механизмам установил изменение сущности, характера и силы связей между компонентов региональной хозяйственной системы и внешней среды. В соответствии с этими изменениями существует преобразования госрегулирования в части региональной экономики, охватывая ее конкретные составляющие.

Различием административно-командной системы, где централизация муниципального управления заключалась в частности по отраслям региональной экономики, в настоящее время взаимоотношения федерального центра с ареалами создаются как отношения с целостными финансовыми 
субъектами. При этом имеет место расширение управленческих функций самих ареалов за счет делегирования возможностей субъектам РФ, а еще внутри самих проблемных ареалов между региональным центром и государственными органами управления [9.С. 104].

Недоступность в РФ научно-обоснованного комплекса мер по стратегическому управлению региональным развитием ориентирует субъекты РФ на выработку личных раскладов к региональному управлению экономикой и моделей социально-экономического благополучия. В комплексе трудностей, с которыми сегодня сталкиваются органы районного управления большей части ареалов государства, одной из ведущих считается неувязка внутри региональной асимметрии - постоянность воспроизведения диспропорций в социально-экономическом развитии отдельных земель предоставленного ареала.

Тут нужно обозначить, что эта предоставленная неувязка не свежая, например, как помощь важных территориальных соотношений в экономике, недопущение излишней степени классификации земель по уровню общественного и финансового становления постоянно являлась ведущей мишенью регулирования ареалов. Трансформация экономики РФ к рыночным механизмам ужесточил внутриобластную асимметрию, собственно, что послужило главным из более неблагоприятных результатов реформационных перемен за последний период. [7.С. 39].

Автор научных трудов А.А. Баширова из всего ряда трудностей, которые приводят к торможению регионального развития субъектов РФ, выделяет два основных типа (рисунок 6).

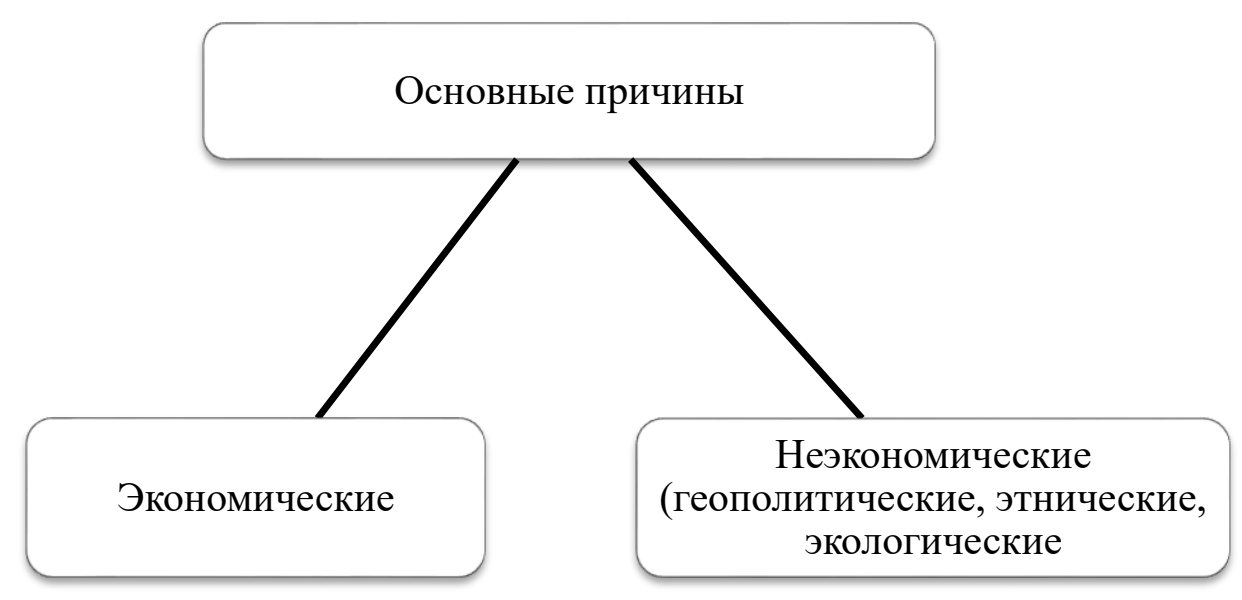

Рис. 6. Виды основных причин проблемных регионов

Источник: [4.С. 38] 
Выше продемонстрированные трудности, какие ощущают ареалы, обладают разным уровнем остроты, также разной длительностью.

Общественно-финансовое запаздывание проблемных ареалов зачастую обременено проблемами общественно-политического, боевого, преступного, народного нрава. Одно из значимых условий, что ухудшает общественнофинансовое запаздывание района, считается природоохранным. Создатели Исянбаев также Чувашаевав в собственных работах показывают образец исследования природоохранного нюанса проблемных старопромышленных, также добывающих ареалов, где долголетняя антропогеновая работа существенно модифицировала естественную сферу ареалов: исчерпывание естественных возможностей, высококачественные, также численные перемены конфигурации основ, неглубоких вод, растительности. Накопление загрязняющих препаратов в рамках областной концепции демонстрирует снижение самоочищающейся возможности природной среды. Тут необходимо выделить, то что в древне индустриальных зонах ранее никак не имеющих природных естественных предметов, подвергаются антропогенному преображению, чему виной сделалась экономично-финансовая работа района. Более этого, анализ экологично характеристик закрепляет стабильную направленность к смещению в худшую сторону состояние сферы жизнедеятельности региональных жителей [6.Со. 219]. Создатели Х.Д.Арсланова, Ш.Д.Арсланов также Л.Г.Шахтаманова в собственных работах фиксируют то, что трудности определенных ареалов имеют все шансы являться обусловленными, равно как преобразованными внутренней структурой общественно-финансовых концепций также в отношениях среди ее концепциями, таким образом также преобразованиями внешней сферы. Множество компонентов внутренней сферы концепции возможно регулировать, в то время как конфигурации внешней сферы, также как принцип, недостаточно поддаются управлению, их принимают во внимание только в мониторингах, также проектах формирования района [2, С.106].

Предпосылкой переломных обстановок в проблемных ареалах, повергнувших к «депрессивности» местности, имеют все шансы являться непредвиденными, в том числе как естественные катаклизмы (природная трагедия), таким образом также техногенные условия (несостоятельность системообразующих компаний). Но практическая деятельность управления проблемными ареалами демонстрирует, то что отрицательные перемены обладают свойством постепенного накопления. Тут важны ряд разновидностей факторов, которые презентованы на рисунке 7. 


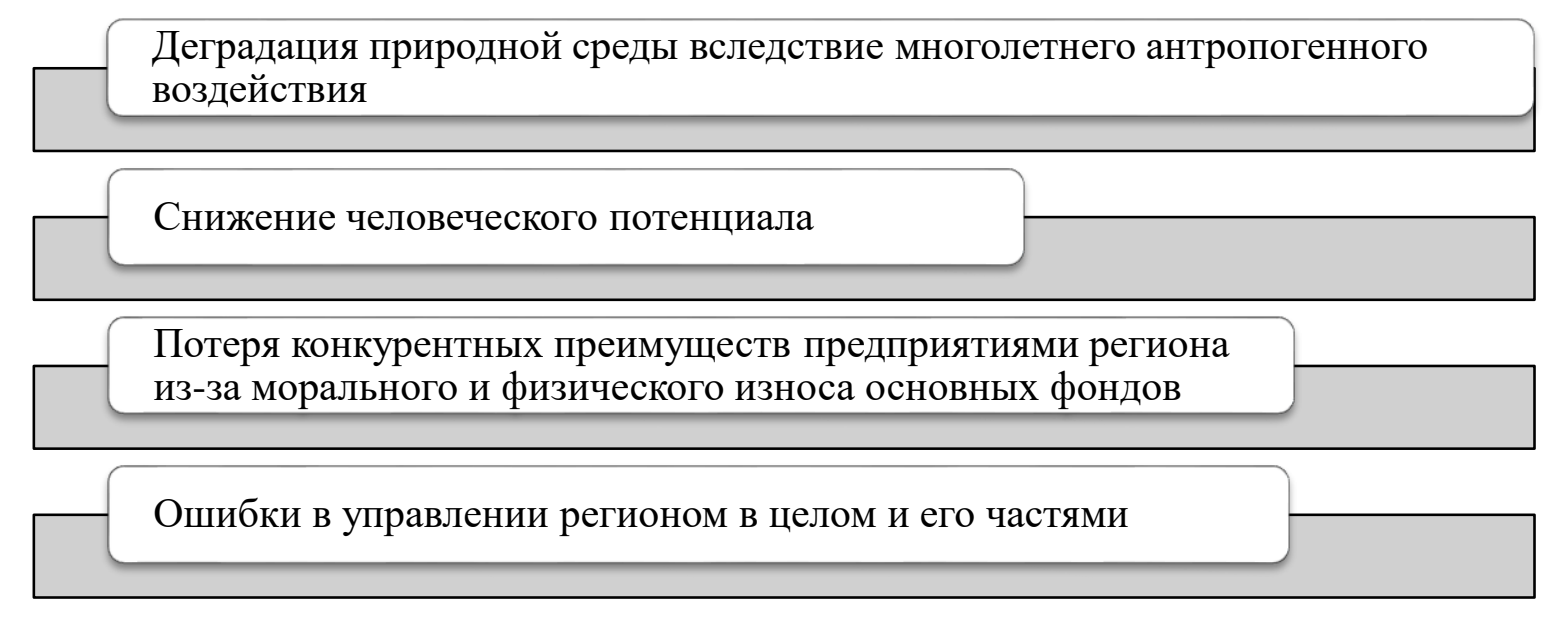

\section{Рис. 7. Причины кризисных ситуаций в проблемных регионах постепенного накопления}

Источник: [8.C. 11]

Одним из ключевых факторов проблемных ареалов считается также переходный промежуток экономики Российской Федерации к рыночным отношениям. Вплоть до 1990 года ареалы обладали сравнительно равномерным становлением, таким образом, Н.Г. Волкова, проанализировав в собственных работах главные характеристики социально-экономического становления субъектов, подмечает, то, что их финансовое несоответствие составляет 8_10раз. С началом перехода к рыночному механизму отставание ареалов содержит быстрое ужесточение, собственно, что было начато из-за неспособности к перестройки имеющихся в этот период концепций хозяйствования, также управления, но с иной - низкой стабилизирующей функцией страны, как главного планового раздела.

Погрешности, просчеты, проблемы перехода к рыночной экономике, которые велись в масштабах целой Российской Федерации, характеризовались прецедентами:

- промышленное изготовление обнаружилось в глубочайшем упадке у прежде градообразующих, машиностроительных, также приборостроительных компаний оборонной промышленности, где преуспевали теневые полукустарные изготовления продуктов общенародного пользования, пищевых товаров, материалов использовавшие для строительства также пр.;

- в определенных ареалах увеличился натуральный монополизм, увеличилось хищение в распределительных сетях;

- ухудшилась общественная инфраструктура ареалов;

- развилась коррупция [5.Co. 11]. 
В результате, главные нюансы оснований проблемных ареалов обладают организационно-управленческий, финансовый, общественно-политический также общественный вид. Главные предпосылки неразрешимости вопросов финансового отставания проблемных ареалов состоят в общественнополитической непостоянности, нехватке природно-экономической возможности, невысокой степенью межотраслевой диверсификации, зависящей от внешних рынков, отсутствии передовых технологий науки, а также техники, негативных инвестиционно-экономических обстоятельствах, нехватке производственных взаимоотношений, также производственной культуры, негативной демографической динамике направленности, несогласованной хозяйственному потенциалу.

Подобным способом, суть определения «проблемный регион» обладает особенной значимостью в создании стратегии экономики государства, что ориентирована на формирование общественно-направленной рыночной экономики, например, как свидетельствует о преградах рыночного изменения в конкретном районе, и о том, что, собственно, не все его мероприятия ,меры, инструменты оказались эффективны собственному назначению.

В любой стране имеются наиболее сформированные в общественнофинансовом взаимоотношении ареалы, таким образом равно как отставание, либо опережение в формировании имеет возможность быть беспристрастно предопределенной различием в ресурсном потенциале, также месторасположением местности. Но образ «проблемный» подразумевает, в первую очередь, в целом, системность в отставании развития эффективных элементов нынешней рыночной экономики, какие также считаются главным тормозящим компонентом в течение результативного самоорганизующегося формирования экономики района, также государства в целом.

Преобразования, которые имеются в конечном промежутке времени совершаются в общественной, также финансовой концепции государства, создают конкретную веру в последующее финансовое формирование проблемных ареалов. Однако в то же время, существует существенное число трудноразрешимых вопросов в формировании ареалов Российской Федерации, какие вынашивают организационно-управленческий, финансовый, общественно-политический также общественный вид.

Субъекты Российской Федерации обладают отличием в основной массе основных общественных, также финансовых характеристиках. И за минувшие года межрегиональное разделение, из-за результатов воздействия внутренних также внешних условий существенно возросла. Сформировавшаяся 
обстановка свидетельствует о нехватке в муниципальных текстурах создание результативных элементов, какие влияют на финансовое формирование ареалов, также на сокращение их дифференциации. Особенно значимым считается обнаружение и формирование ценностей также граней, какие принимают во внимание территориальную особенность проблематичных ареалов, также характерные черты с целью свершения финансовых и общественных характеристик формирования.

\section{Список литературы}

1. Амирова Э.А. Объективная необходимость выравнивания уровня социально-экономического развития регионов РФ // Экономика и бизнес: теория и практика. 2020. № 9-1(67). С. 29-31.

2. Арсланова Х.Д., Арсланов Ш.Д., Шахтаманова Л.Г. Институты регионального развития в условиях проблемных регионов: возможности и перспективы // Региональные проблемы преобразования экономики. 2018. № 11. C. $155-163$.

3. Балакина Г.Ф., Колоскова Н.В. Инструменты финансового регулирования социально-экономического развития проблемного региона // Экономика Профессия Бизнес. 2020. № 3. С. 5-14.

4. Баширова А.А. Инновационный фактор в социально-экономическом развитии проблемных регионов // Вопросы структуризации экономики. 2018. № 2. C. 37-40.

5. Волкова А.Г. Проблемные аспекты управления неравномерностью социально-экономического развития региона и пути их преодоления // Регион: системы, экономика, управление. 2019. № 4(47). С. 10-14.

6. Исянбаев М.Н., Чувашаева Э.Р. Проблемы модернизации промышленности региона // Московский экономический журнал. 2019. № 13. С. 215-224.

7. Пшиканокова Н.И., Куек 3.Н., Пшиканокова Н.Д. Новые подходы к разработке и реализации стратегий социально-экономического развития региона в условиях экономических санкций // Вестник Адыгейского государственного университета. Серия 5: Экономика. 2018. № 2(220). С. 38-49.

8. Силова Е.С. К проблеме устойчивого развития региона // Вестник Челябинского государственного университета. 2017. № 5(401). С. 7-14.

9. Тамов А.А., Тамова М.К., Тамов К.А. Особенности проблемного региона как фактор его стратегического развития // Вестник Адыгейского государственного университета. Серия 5: Экономика. 2018. № 3(225). С. 103-108. 